\title{
Realising Information Technology Benefits in the Health Sector - the Management Education Agenda
}

\author{
Professor E.A. More \\ Graduate School of Management, \\ Macquarie University, N.S.W. 2109; Ph: +61 2 8509000; Fax: \\ +612 8509942; Email: elizabeth.more@mq.edu.au \\ Dr. D.G. More, \\ More \& Associates, \\ 4 Ronald Ave., Greenwich, N.S.W. 2065; Ph: +61 2 4382851; \\ Fax: +61 2 99067038; Email:davidm@asstdc.com.au
}

\begin{abstract}
Worldwide the Health Service Delivery Sector is undergoing enormous change and turmoil. Substantial investment in Information Technology (IT) might help make such change more survivable, but to date only a low level investment in IT has occurred within the sector. This relates to relatively limited understanding of IT's real potential in improving the quality of patient care, reducing cost, and improving operational efficiency.

In this paper we make a twofold argument: (a) IT is a key enabler of the type of improvement sought by the sector in quality, patient satisfaction and cost-effectiveness of care delivery, and that, central to the effective implementation and ultimate achievement of such benefit, is a fundamental paradigm shift in the attitude of Australian health service management to the value of information; and (b) structured management education programs (covering the managerial aspects of deploying IT and managing benefits), tailored for health industry managers, must be central to both initial and ongoing health industry education and training programs. Without such management education in the sector the expectations for major improvement by decade's end will not be realised.
\end{abstract}

\section{Keywords}

Information technology management; health industry; management development; technology benefits 


\section{INTRODUCTION}

Many trends are converging to demonstrate that the world future managers face is qualitatively different to that of the more recent past and present. Alongside the well recognised ones such as globalisation, and increased competitiveness, one critical trend is that of the emergence of the information based economy and society, dependent on telecommunications, computing, and mass media - and, increasingly on the merging of these three into multimedia. The consequences for management practice and education are clear - we must revise requirements in an environment of increased information needs and technological complexity (Waddock, 1991). While some reassessment of management education requirements has occurred generally, very little has focussed on the needs of specific professional areas and sectors, including that of medicine and the Australian health industry. This paper seeks to address such needs, focussing on the role of IT as content.

\section{AUSTRALIAN MANAGEMENT EDUCATION}

In Australia the late 1950s and 1960s saw the beginnings of systematic management education. During the next three decades, management education was stimulated by three Commonwealth Government committees of inquiry or task forces led by Richard Cyert (1969), John Ralph (1980), and most recently by David Karpin (1992).

Karpin's report, released in 1995, focussed on "the way Australia prepares its managers for work and leadership" (Karpin, 1995, 1). Karpin argued $(1995,2)$ that "excellent leaders and managers require well structured, systematic education and continual development so that they can add maximum value to the national economy through their performance within their enterprises." Within the report a 'new' paradigm of management was emphasised, along with a new profile of senior management into the 21 st century, highlighting elements such as the move from inflexibility to flexibility, the move from administration to leadership, and organisational learning and empowerment over autocracy and bureaucracy.

The five key challenges for Australia identified in the report are those of: upgrading vocational education and training and business support; capitalising on the talents of diversity; achieving best practice management development; reforming management education; and, underpinning all, creating a positive enterprise culture throughout the community culture. In meeting such challenges, the Task Force identified eight main areas in which Australian managers need to improve their skills (1995, xxxix): soft or people skills; leadership skills; strategic skills; international orientation; entrepreneurship; broadening beyond technical specialisations; relationship building skills across organisations; and utilisation of diverse human resources.

The report's curricula recommendations for management education include such priority topics as functional requirements, internationalisation, communication, team building, and leadership. Not surprisingly, the other priority topic area is that of IT. 


\section{MANAGEMENT EDUCATION AND THE HEALTH SECTOR}

While management in the health sector encompasses a variety of professional and nonprofessional areas, much of the more recent medical management literature emphasises the meaningful impact physician-executives can have on the health care system (e.g. Betson, 1986; Curry, 1988). The basis for this perspective is the assumption of such individuals having the necessary capability to influence others so as to make an important difference in managing health care organisations. Here communication and information processes are, of course, imperative considerations (Garko, 1994).

Given the unprecedented change the Australian health care system is undergoing, the active management education of professionals in that system is critical. Few professionals in the sector do, however, undergo management education during the course of their initial degrees and many not even after that period. Given the change to "a highly complex, regulated, group-oriented, multi-institutional (and, increasingly, forprofit) form of organisation and financing (Montgomery, 1986, 17)", this is a serious omission. When coupled with the dictates of an increasingly technologically sophisticated sector and an information society, it is inexcusable.

Fortunately, there is some recognition of this problem. A variety of approaches have been adopted including, for example, the growing numbers of individuals from the health sector undergoing postgraduate qualifications in MBAs, and the rise of short courses, such as that run by the Western Sydney Area Health Service each year - the one week live-in Management For Clinicians course. Such courses, however, do not necessarily incorporate the requisite emphasis on sector IT management.

\section{THE AUSTRALIAN HEALTH SYSTEM}

The Australian Health System is a large, complex and expensive component of the national budget with total spending on health care now approximating \$35B: direct Commonwealth and State funding provides $60 \%$ of this figure and the private sector contributes the rest (AIH\&W, 1994) In 1995/6 it is expected Australia will spend approximately $9.0 \%$ of national Gross Domestic Product on Health. This large and gradually increasing expenditure has been a source of continuing concern to successive governments but, despite quite draconian attempts, the overall figure has continued to rise.

Of particular concern to most analysts has been the difficulty in establishing just what is purchased for the overall expenditure and just how efficient and effective are the basic service delivery mechanisms. These concerns have led to an increasing government emphasis on the provision, by service delivery units, of progressively more comprehensive information regarding costs, activity and outcomes. Similar pressures are also seen in the private sector as Health Insurance Funds seek increasingly more detailed information and negotiate ever more complex arrangements with service providers. Such external pressures as these, combined with emerging competition between service providers, and internal needs on the part of managers to understand better their operations, are making the use of much more extensive IT in this sector inescapable and inevitable. 


\section{THE PLACE OF IT IN THE MANAGEMENT OF THE HEALTH SERVICE DELIVERY SECTOR}

The Health Sector in the 90's is managed by a range of people. In addition to the traditional administrators it is, as suggested above, increasingly observed that clinical staff (both doctors and nurses) are involved in a great deal more management and are having both extra responsibility and accountability forced upon them. It is, therefore, clear that any development of any management education agenda for health service delivery personnel must involve these staff, and that systems must be accessible and useable by a range of people from widely varying backgrounds.

Managers in the sector need information which assists in operational decision making and depending, on their role, information also for strategic decision making. In addition, with the emergence of 'managed competition' and the requirement to negotiate contracts with various payers, patient costing information, and sophisticated modelling capability are both critical.

In order to manage in an operational sense, excluding individual clinical data which is used for individual patient decision making, the following information is clearly useful: financial performance, human resource, and departmental activity information. Moreover, in addition to this basic information, it is important to develop appropriate performance indicators for each area or function, enabling the tracking of performance over time and continuous improvement management approaches.

For strategic decision making a range of performance indicators are required including cost/profitability related to patient volume, patient illness, patient doctor, patient diagnostic related group and patient product line; patient referral sources and origins; and patient demographics, insurance rates, etc to assist in market identification and analysis. This information will permit the organisation to identify those areas of activity which are profitable if profitability is an issue and allow comparison with other similar organisations, in benchmarking terms, to identify areas for review.

For negotiations with payers, the main information required is patient costing information in ways that allow appropriate deals to be negotiated, no matter what mix of work the payer wishes to contract for. In some situations competitive intelligence may also be required to obtain the best outcome.

In order to provide this information in a timely, accurate and easily digested fashion, very well developed IT infrastructure is required. In a hospital, the high level architecture needs to look similar to the following figure: 


\section{CLINICAL \& FINANCIAL MANAGEMENT SYSTEMS}

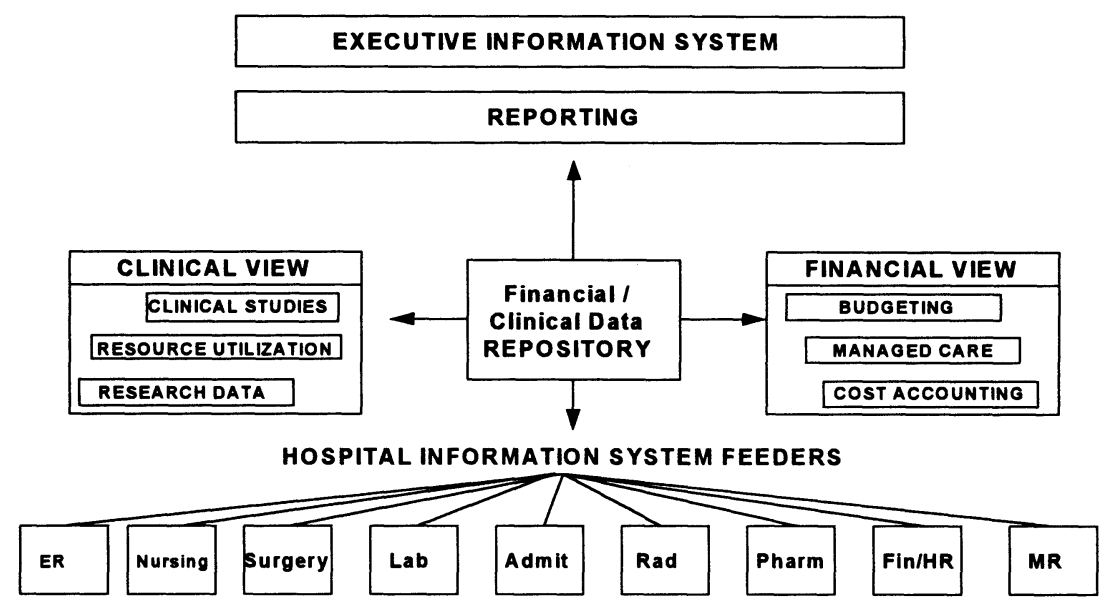

Figure 1 The high level architecture of the Hospital.

With this level of infrastructure in place the previously outlined requirements can be met, but there remain two central issues which need to be addressed. First, the process of implementation and ongoing management of such a complex infrastructure; and second, developing the skills of managers so they can optimally exploit the information now available to them.

\section{HEALTH SECTOR MANAGEMENT ATTITUDES TO IT}

In 1994 the Australian College of Health Service Executives conducted a survey (unpublished) of its membership to assess their views on the directions that would be taken in the Australian Health System between 1994 and the year 2000. With respect to the place and value of IT overall, the over 800 respondents indicated that IT was not delivering the benefits required and the necessary linkages between financial, activity and clinical information were not being successfully made. Despite this view, paradoxically, there was a very high level of confidence that by the year 2000 both the level of investment and the value received from that investment would dramatically improve. Indeed, many respondents believed that improved IT and introduction of 'Quality Management Principles' were the two things likely, at a management level, to save the overall quality and level of care in the system.

This attitude seems somewhat naive. It is clear, and has been for the last decade, that health sector management cannot continue to hope for 'magic bullet' type externally provided cures to their need for reform and enhanced efficiency. The incremental and evolutionary approach is no longer working and the time for major efforts at radical business transformation, which will need information technology as an enabler, has well and truly arrived.

The problem is that, as a group, until now, investment by health sector management in IT has been very much less than required, and the basic technology infrastructure 
still does not exist in many organisations to enable the deployment of the technologies required for such business transformation to be undertaken. In Australia the problem is more acute than in the U.S. where, presently, investments of between $3-4 \%$ of operating revenue are going to IT on average in the hospital sector, compared with 1$2 \%$, at best, in Australia.

The challenge before the sector is, as one of a number of major initiatives, to have its management learn how to successfully deploy and exploit IT for the benefit of the overall health system. Before, however, outlining our view of the high level issues which need to be addressed in a successful management education plan in this area, it is important to discuss a number of points related to the extraction of benefit from IT investments.

In brief, it is widely recognised that benefits from IT come in two forms: (a) those resulting from the basic capacity of the technology to carry out many tasks with speed, accuracy and consistency; and (b) those flowing from the way well considered deployment of technology can change the way work is undertaken and enable business processes to either be improved, or, on occasion, totally transformed. While the detail of how benefits can be optimally obtained is beyond the scope of this short paper, a few key points can be made. These include the following:

- The redesign and transformation of business processes is something undertaken by a business area and not by the MIS department. Thus management of all business units requires knowledge of both the capability and possibilities of IT.

- Selection of software and systems to enable improvements to be made is a process where the IT/MIS Department sets the technical environment and the business unit should determine what will work best for them from the available choices.

- Development of performance indicators to assess the success of any implementation should be undertaken by, and agreed with, the business unit and the responsible business unit manager should then be accountable for delivering the promised benefits (and development of a business case for each substantial implementation is a useful discipline to assist in identification of potential benefits).

- Once developed, good performance indicators can be valuable in developing an ongoing 'continuous improvement' approach to a business area following initial system implementation.

\section{A SUGGESTED CURRICULUM FOR AN IT MANAGEMENT EDUCATION PROGRAM IN THE HEALTH SECTOR}

From the preceding discussion it will be clear that, for success, the management education program for Health System Managers must seek to emphasise the following areas of competency: first, the area of system implementation, and, second, the area of strategic and operational use of information.

Before suggesting a high level course outline, it is important to recognise that the problem to be addressed is of considerable practical importance and is by no means purely an academic concern. The history of hospital information system implementations in Australia is littered with cost overruns, lack of benefits delivery, and, on occasion, quiet catastrophic failure. The most recent example of this can be 
seen in the 1995 decision, on the part of the NSW Health Department, to de-install patient management systems in a number of major hospitals where they were already operational, after well in excess of \$20million had been spent on their implementation. We are confident that such waste would not have occurred had more of the senior management of the Hospitals involved, and the Department in general, been familiar with the material covered in the program that follows.

The reality is that the Health System cannot wait for a new generation of managers with the skills and competencies outlined above to reach the position where they will have responsibility for system implementations and decision making required to make a substantial difference. Thus, it will be necessary, if major improvement is to be achieved, to provide incremental short course based training in appropriate settings, probably under the auspices of the various management and health management schools. The areas which need to be addressed include:

\subsection{Basic Information Technology}

- Introduction to the Basics of IT

- Current and Future Role of IT in the Health Sector

- The Transforming Potential of Information Technology

- Elements of Process Based Analysis and Redesign.

\subsection{System Implementation}

- Approaches to Information System Selection

- The Principles of Project Management

- IT Project Risk Management

- Change Management

- Approaches to the Development of Performance Indicators

\subsection{Information Deployment.}

- Basic Principles of Information Management

- The Operational Use of Information for increased Efficiency and Effectiveness

- The Strategic Use in Information to obtain Performance Improvement and a Competitive Edge.

We would envisage that the first two sections of the suggested program would take an initial week and that a second week be devoted to the delivery of the third section. A case study based approach would be ideal for sections 2 and 3 and would ensure the interest of participants was retained. In parallel with this program we would, of course, strongly encourage provision of a similar programme to all relevant undergraduates.

\section{CONCLUSION}

If management education is to be successful in educating Australian managers for today and tomorrow, rather than for yesterday, we must pay attention to developing global trends, including technological ones, and make curricula responsive to dramatic changes affecting management practice. Given the pivotal role of the Health Care sector in any society, clearly IT management in this sector must also be addressed. 
Unfortunately, understanding the effective use of IT does not exist in sufficient depth within Australian Health Management at present. If education for such management is not remedied within the next few years, we can all expect to see delivery of a lower quality of patient care at a substantially greater cost in the near future.

\section{REFERENCES}

Australian Institute of Health and Welfare (1994) Australia's Health 1994: the fourth biennial health report of the Australian Institute of Health and Welfare. AGPS, Canberra.

Betson, C. (1986) Managing the medical enterprise: A study of physician managers. UMI Research Press, Ann Arbor, MI.

Curry, W. ed. (1988) New leadership in health care management: The physician executive. American College of Physician Executives, Tampa, Fl.

Garko, M. (1994) "Communicator Styles of Powerful Physician-Executives in Upward-Influence Situations." Health Communication, 6 (2), 159-172.

Karpin, D. (Chair) (1995) Enterprising Nation. Report of the Industry Task Force on Leadership and Management Skills. AGPS, Canberra.

Montgomery, K. (1986) "Today's physician manager: A new breed." Physician Executive, 12 (5), 14-17.

Radecki, L. (1986) "The making of physician managers: A training approach." Management Review, 75 (10), 14-15.

Waddock, S. (1991) "Educating Tomorrow's Managers." Journal of Management Education, 15 (1), 69-95.

\section{BIOGRAPHY}

Professor Elizabeth More is Deputy Director, Director of Research at the GSM, Macquarie University. Her particular areas of research interest are in organisation studies, and communications technology and policy. She has presented numerous papers locally and internationally and published widely in these areas; her latest monograph is (with M. McGrath) Cooperative Corporate Strategies In Australia's Telecommunications Sector - The Nature of Strategic Alliances, 1996, published by DIST/AGPS, Canberra. Dr. David More is a Director of More \& Associates, a consulting firm in the area of Health IT. He has a PhD in Clinical Pharmacology, specialist medical qualifications in Intensive Care and Anaesthetics, and has worked for the N.S.W. public hospital sector and as a Director of Health Services Consulting for Ernst \& Young. 